\title{
Research on Internet-based Teaching of English Newspaper Reading
}

\author{
Xueai Zhao 1,a, Yingcong Zhao ${ }^{2, b}$ \\ ${ }^{1}$ School of Humanities, Economics and Law, Northwestern Polytechnical University \\ Xi'an, 710129, China \\ ${ }^{2}$ School of Humanities, Economics and Law, Northwestern Polytechnical University \\ Xi'an, 710129, China \\ aemail: xazhao@nwpu.edu.cn, bemail: 345369391@qq.com
}

Keywords: constructivism; network environment; English newspaper reading teaching

\begin{abstract}
In order to develop Chinese student's ability in reading English newspaper, the authors innovatively designed an internet-based teaching model for English newspaper reading course based on constructivism. Through a comparative study, the authors concluded that the new teaching pattern of English newspaper reading under network environment is more efficient in raising students' reading ability than the traditional one. This new attempt in English newspaper reading teaching will introduce internet into English teaching reform in China, and promote the development in this field.
\end{abstract}

\section{Introduction}

English newspaper plays an important role in informing Chinese students of major national and international political, economic and cultural events and broadening their view of sights. Meanwhile, the vivid and diverse news materials benefit students a lot in terms of nurturing their sense of language and helping them master authentic English expressions. At present, many universities and colleges have opened English newspaper reading course for English majors of the third and fourth grade. Conferences on teaching of this course are regularly held in China, studying the corresponding teaching concept and teaching mode. [1] Different scholars put forward different views respectively on news stylistics, the selection of teaching material, teaching content arrangement, teaching techniques and so on. To a certain extent, English newspaper reading teaching and research have gained great development with the collaborative efforts of all members in teaching fields. However, so far, researches and practices of internet-based English newspaper reading directed by pedagogy, psychology, language learning theories are quite few. Most teachers still rely on their own experience but fail to make full use of various teaching media like newspapers and magazines, electronic projector, multimedia, network and so on. This paper introduces constructivism into newspaper reading teaching, represents the results of an empirical study on the internet-based newspaper reading teaching in Northwestern Polytechnical University, and compares the internet-based teaching approach with the traditional one in improving students' reading test scores. The study result verifies the superiority of internet-based teaching, and analyzes the characteristics of the newspaper reading teaching under network environment.

\section{Theoretical Basis-Constructivism}

Constructivism is firstly put forward by Swiss philosopher, psychologist J. Piaget[2]. Piaget studies cognition from activities-action perspective. His theory highlights people's initiative role as cognition subject, and emphasizes that cognition is a kind of structure. Without the constructivist activity of the subject, it is not possible to generate knowledge.

Constructivist view of teaching can be summarized as follows: (1)Teaching is to create a helpful environment for constructivist learning. This kind of learning environment can provide appropriate 
cognitive tools, and encourage learners to construct meaning through interaction with environment. (2)Teachers should construct a learning community that facilitates information exchange, knowledge construction and classroom collaboration. (3)Teachers should pay attention to the social participation of learners and real learning activities and contextual content. (4) Knowledge can not be acquired in a ready-made isolated way. The teacher should emphasize the multiple representations of the knowledge. (5)Teachers should firmly stick to the context principle to design an environment that supports tacit knowledge learning, so that students can perceive the knowledge they need subtly under the influence of the surroundings. [3]

The hypermedia network is beneficial to learners' autonomous learning. Virtual technology helps learners with situational learning while network communication technology facilitates learners in collaborative learning. Obviously, network teaching offers a learning environment which is consistent with constructivist and student-centered theories. Therefore, the environment offered by the teaching of network-based newspaper reading corresponds with the theory of constructivism, and fully reflects the innovative, situational and social factors in students' learning. Thus it is feasible and necessary to use constructivism to guide English newspaper reading teaching.

\section{Integral Design of Newspaper Reading Teaching and Empirical Experiment}

(1) Integral design of newspaper reading teaching

The construction of newspaper reading network in Northwestern Polytechnical University is as follows: Teachers edit the downloaded reading material in such different formats as audio, video documents and input them into a computer server, which connects with another 21 computers, forming a local area network. Students in class log on the local area network and select proper reading material according to teaching schedule and requirements. Before each class, teacher assigns the class learning tasks, and provides some questions for them to answer. In the class, the students are able to master learning progress and select reading material on their own. After self-reading and thinking, they reflect their learning results either in form of written answer or group presentation.

Under such network environment, students make full use of their initiative, and achieve the transformation from passive receiving knowledge to active seeking new knowledge. At the same time, the reading material, which is divided into several modules based on reading subjects, realizes the situational learning. Besides, a variety of news video and audio tips give students a full sensory understanding on hot topics, and make them feel like personally being on the scene. Finally, through group discussion and presentation, the new teaching method enhances mutual cooperation among students, helps them overcome the fear of answering questions and encourages them to participate in class activities.

(2)Experimental design

In order to compare the differences between the newspaper reading teaching under network and the traditional classroom environment in their teaching quality and efficiency, the authors designed an empirical experiment. The authors randomly divided the third-grade English majors in Northwestern Polytechnical University into two groups - experimental and control group. The experimental group attends classes in the multimedia classroom with a local area network. Their reading material includes multimedia courseware, network audio and video and text files. Classroom activities are conducted in the process of raising questions-teacher collaboration - students' autonomous reading - results display. Control class studies in traditional classroom and read only written material offered by the teacher. The class goes along the process of raising questions, reading materials, answering questions and reviewing important linguistic points. To ensure the validity and accuracy of the experimental results, the authors controlled several important variables in the experiment. So the experiment guaranteed that the teachers of both classes are of the same level, the teaching hours and subjects are the same. After ten weeks, the performance of two groups was compared and conclusion was drawn. 
(1) Subjects of the experiment

Subjects of this experiment are third-grade English majors in Northwestern Polytechnical University, totally 42 people. They were randomly divided into experimental group and control group, each consisting of 21 students. Then the scores of their English extensive reading course in the second semester of sophomore year were collected for independent samples $t$ test (Sig. (2-tailed) $0.961>0.05)$. The result shows that there was no significant difference in students' reading ability between the experimental class and the control class.

(2) The research tool

As for the research tool, the authors designed two tests for students to take before and after the experiment, the difficulty of which are at the same level. Each test is composed of 4 passages, which are all from CET4 test in 2012. The form of the test is multiple choice and brief question answer. Test score is 100 points, test time is 60 minutes. The Pearson Correlation Coefficient of two tests is 0.687 . Data are analyzed by social science statistical analysis software SPSS13.0.

(3)Data collection and analysis

Two groups received the test of reading ability respectively before and after the experiment was carried out. All scores were input into the computer, and were treated with SPSS 13. 0. After paired samples $\mathrm{T}$ test analysis, the authors tried to answer two questions: (1) Are there any significant differences in reading test scores within two groups before and after the experiment? (2) Are there significant differences in reading test scores between the experimental group and control group after the study?

\section{Results and Discussion}

(1) The experimental results

After ten weeks of experiment, the scores of two groups are as follows:

Table 1: test scores of both groups

\begin{tabular}{|c|l|l|}
\hline & pre-test & post-test \\
\hline control group & 81.85 & 84.04 \\
\hline experimental group & 82.61 & 88.46 \\
\hline
\end{tabular}

Through the comparison of test scores before and after the experiment, it is easy to conclude that, after a 10-week training, the reading ability of two groups has been improved to an extent. The post-test score of control group was 84.04 points, which was 2.19 points higher than the pre-test score 81.85 points. The experimental group also made a progress in the test score after the experiment, with 82.61 and 88.46 points as pre-test and post-test score. However, in comparison with the control group, the post-test result of the experimental group is over 4 points higher than that of the control group. By conducting a paired samples $t$ test (Pair. ( 2-tailed) is $-2.093<0$. 05), the authors found there was a significant difference between the per-test scores of the two groups. So it can be concluded that the teaching of English newspaper reading under the network environment has obvious advantages over traditional teaching in raising students' ability of reading, comprehending and analyzing reading material. The above experiment provides data support for the priority of network teaching, while the following paragraphs give a detailed explanation of its advantages.

(2) The advantages of newspaper reading teaching under network environment

The traditional teacher-centered teaching pattern of English newspaper reading treats teachers as disseminators of knowledge, and students as passive recipients of knowledge. As a result, students' enthusiasm and initiative and creativity can not be played into full extent, which in turn affects the teaching efficiency. However, under the network environment, teachers are the organizers and monitors of the class, while the students become the real subject of information processing and the 
initiative constructor of knowledge. With the assistance of the rich online resources and network technology, network teaching fully demonstrates its characteristics of flexibility, individualized teaching, real-time and the autonomy. It also fully reflects the constructivist philosophy of education, which can not be found in the traditional teaching. In brief, newspaper reading teaching under network environment has unparallel advantages and merits over traditional teaching.

(1) Novel and real-time teaching material

In contrast with the traditional paper-based reading material, internet-based newspaper reading material has following advantages: First, the reading material is various in forms, ranging from multimedia courseware to network video and audio. It is rich and novel in content, and vivid and interesting in nature, easy to arouse the students' interest and enthusiasm in learning. Second, the reading material covers a wide range of subjects. Different forms of reading data on a certain topic show a whole picture of an event in a comprehensive and objective way. Third, the downloaded reading material is updated and real-time, embodying large amounts of authentic English expressions, which help students to know about the style and regular expressions of English newspaper language.

(2) Interactive teaching activities

Network teaching mode has brought university English teachers an important change in role. The special mode of network structure objectively determines that students are the main body while teachers are only directors in the teaching activity. Therefore, one of the main characteristics of network teaching model different from the traditional one is that students become the major part of learning process, which gives birth to the transformation from teacher-centered to student-centered mode. Teachers under network teaching environment mainly undertake the task of regulatory organization and guidance of whole teaching process. Students become the center of teaching and the subject of all teaching activities. So the arrangement and implementation of teaching activities should meet the learning demands of students. In the class, students can realize their collaboration, understand their own learning in length, and learn from others' learning experience through classroom discussion. As for teachers, it is easy for them to master students' learning conditions, and in turn flexibly adjust the teaching plans to assure the teaching quality.

(3) Individual, hierarchical teaching design

The advantage of network-based teaching makes hierarchical and individual teaching become possible. [4] In the traditional classroom, the number of students is so large that teaching can only satisfy the requirements of the majority, leaving individual personality of students not considered. However, in the network teaching classroom, teachers can make different levels of teaching plans and teaching goals according to students' specific conditions. Students with different levels of abilities can choose the content and the way of learning according to their actual situation and interest. In this way, teachers can also provide individual guidance, find out problems and give students corresponding feedback, so as to ensure the realization of personalized teaching, greatly stimulating the learning enthusiasm of students and effectively cultivating their autonomous learning ability.

\section{Conclusion}

In summary, compared with traditional teaching model, the internet-based newspaper reading teaching method can greatly improve students' reading ability. It also boasts several advantages in reading material, classroom participation and so on, which can overcome the defects and deficiencies of traditional teaching. It is also beneficial to training autonomy and creativity in students. Therefore, teaching under network environment should become a direction for university English teaching reform. However, some problems still exist in internet-based university English teaching, which requires the collaborative efforts from both schools and teachers to strengthen the development and design of English network teaching software, improve the research and study of network teaching mode and adhere to the student-oriented teaching concept, so as to mobilize the 
learning enthusiasm in students, improve the teaching level of teachers and realize the enhancement teaching effects.

\section{References}

[1]Xuemei Wang, Weidong Dai, On the Teaching Strategies of English Journals and Newspapers from the Perspective of Web Environment, Computer-assisted Foreign Language Education, Shanghai, 2005(8), pp.13

[2] Piaget J. The Principles of Genetic Epistemology, Routledge \& Kegan Paul Ltd, Lon don, 1972 , pp. $235-230$

[3]Zhixian Zhong, Constructivist Learning Theory and Teaching Design, E-education Research, Lanzhou, 2006 (5), pp.12-13

[4]Xiaoheng Fu, On Network Teaching of College English, [J] Education and Vocation, Beijing, 2007(3), pp.27 